\title{
A rare case of skin blistering and esophageal stenosis in the course of epidermolysis bullosa - case report and literature review
}

\author{
Agata Michalak', Halina Cichoż-Lach ${ }^{1 *}$ (D), Beata Prozorow-Król', Leszek Buk² and Monika Dzida²
}

\begin{abstract}
Background: Epidermolysis bullosa (EB) constitutes a heterogenous group of rare multisystem genetically transmitted disorders comprising several blistering muco-cutaneous diseases with a monogenic basis and either autosomal dominant or autosomal recessive mode of inheritance. EB manifestation is not only limited to the skin. Systemic signs might involve the nose, ear, eye, genitourinary tract and upper gastrointestinal tract. The presence of particular symptoms is directly determined by a type of altered skin protein. Gastrointestinal manifestation of EB is most commonly reflected by esophageal stenosis due to recurrent esophageal blistering, followed by consequent scarring.
\end{abstract}

Case presentation: Here we present a case of a man with dystrophic EB and dysphagia, skin blistering, joints contractures and missing nails. To our knowledge, the presented man is the oldest one diagnosed with EB living in Poland.

Conclusions: Management of an esophageal stricture in such circumstances is based on endoscopic dilatation. However, in most severe cases, placement of a gastrostomy tube is required. Despite great advances in medicine, a targeted therapy in the course of EB has not been established yet.

Keywords: Epidermolysis bullosa, Esophageal stricture, Dysphagia, Endoscopic dilatation

\section{Background}

Epidermolysis bullosa (EB) is a broad entity which encompasses several types of genetically transmitted blistering disorders: EB simplex (EBS), junctional EB (JEB), dystrophic EB (DEB) and Kindler syndrome (KS). The division is mainly based on the level of skin cleavage. Extensive skin blistering as a result of minimal mechanical trauma is a key feature in the course of EB. Degeneration of particular types of skin proteins determines the presence of extracutaneous manifestation, whose range varies among EB subtypes [1, 2] (Fig. 1).

\footnotetext{
* Correspondence: lach.halina@wp.pl

'Department of Gastroenterology with Endoscopy Unit, Medical University of Lublin, Jaczewski Str, Lublin 820-954, Poland

Full list of author information is available at the end of the article
}

\section{Case presentation}

A fourty-year-old man with DEB diagnosed at the age of eight was admitted to the department of gastroenterology because of the dysphagia for two previous months. The diagnosis of DEB was established due to the presence of single blisters on the whole body since the sixth month of life. His sister was also diagnosed with DEB and had similar symptoms of the disease. To our knowledge, the presented patient and his sister are the oldest diagnosed with EB living in Poland. At the age of four the patient started experiencing heartburn occasionally. Five years later dysphagia appeared for the first time. It was an episodal and periodical ailment. He reported a deterioration of dysphagia at the age of nineteen; he mostly consumed liquids and soft consistency meals during that time. Nonetheless, the patient admitted that this esophageal discomfort still was not a constant one and there were time intervals 


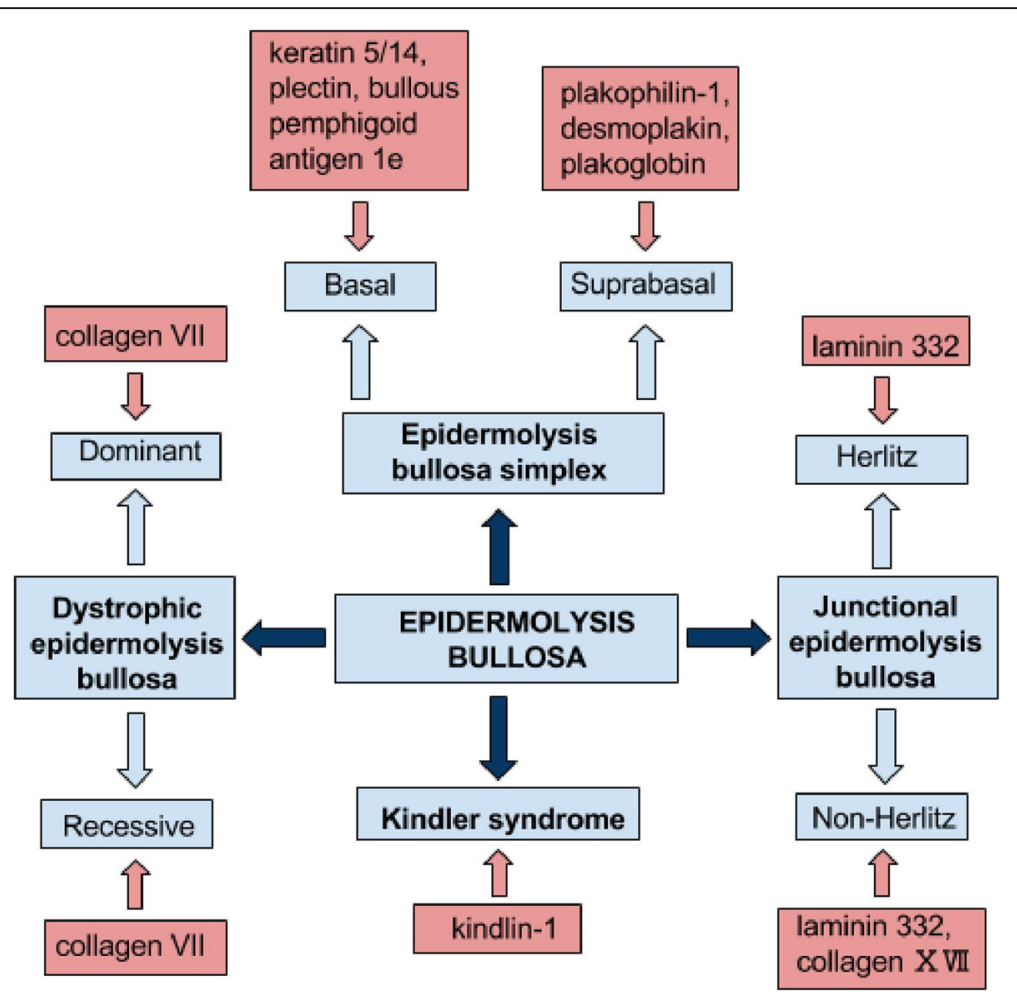

Fig. 1 Types of epidermolysis bullosa with involved skin proteins

without this ailment. In the past there were also episodes of mild esophageal bleeding. The only one endoscopic esophageal dilatation in this patient took place in 1997; a stenosis was located then approximately $18 \mathrm{~cm}$ from incisors. The performed procedure ameliorated swallowing difficulty. A barium swallow test obtained one year after the endoscopic dilatation of the esophagus also revealed esophageal constriction on the same level. In 2014 the patient was diagnosed because of hematochezia and pain in hypogastrium. Tissue samples obtained in colonoscopy revealed the presence of nonspecific inflammatory infiltration in the ascending colon and terminal part of the ileum. Interestingly, 3 years ago he complained of hemoptysis and there was a suspicion of bleeding to pulmonary alveoli in the course of DEB. However, a CT scan did not confirm bleeding. On admission to our department the patient was complaining of painful swallowing of solids. Two months earlier he was diagnosed in the cardiology unit because of the chest pain and elevated level of troponin I. An electrocardiogram did not show any abnormalities. The patient refused to undergo coronarography and no more cardiological diagnostic procedures were performed Additional file 1. On admission to our unit he did not complain of the chest pain. On physical examination he appeared comfortable, afebrile with pulse 90 beats per minute, blood pressure $125 / 90 \mathrm{mmHg}$, respiratory rate 19 per minute and the body mass index (BMI) was $24.7 \mathrm{~kg} /$ $\mathrm{m}^{2}$. The patient presented blisters, skin reddening and crust formation on the upper and lower limbs. There were also contractures and disabled movement in his hand joints together with a loss of a finger and toenails (Fig. 2). The apex of the tongue and left palatine arch were covered by superficial ulcerations. During his hospital stay, performed laboratory tests did not reveal any abnormalities. A CT scan of the chest and abdomen showed a thickening of the esophageal wall at maximum to $7 \mathrm{~mm}$ on the level from the fourth cervical vertebra to the fourth thoracic vertebra (Fig. 3). A probe of gastroscopy under sedation with benzodiazepine failed due to an esophageal stenosis. An attempt of examination with paediatric endoscope was also unsuccessful. A barium swallow test revealed a narrowing of upper esophageal lumen to $7 \mathrm{~mm}$ along the length of $4 \mathrm{~cm}$ together with two diverticula on the right side not emptying of contrast. During swallowing other two diverticula appeared which were emptying of contrast (Fig. 4). A barium swallow test also showed a noticeable weakening of the esophageal mucous membrane. After the performed investigation the patient was qualified to endoscopic dilatation of esophageal stenosis and endoscopic management of diverticula. However, he did not agree to undergo this procedure during current hospital stay. In our unit the patient was treated with proton pump inhibitor (PPI) and prokinetic drugs 




Fig. 2 Contractures in hand joints and crust formation (a), blisters (b), loss of a finger and toenails (b and $\mathbf{c})$, skin reddening (d)

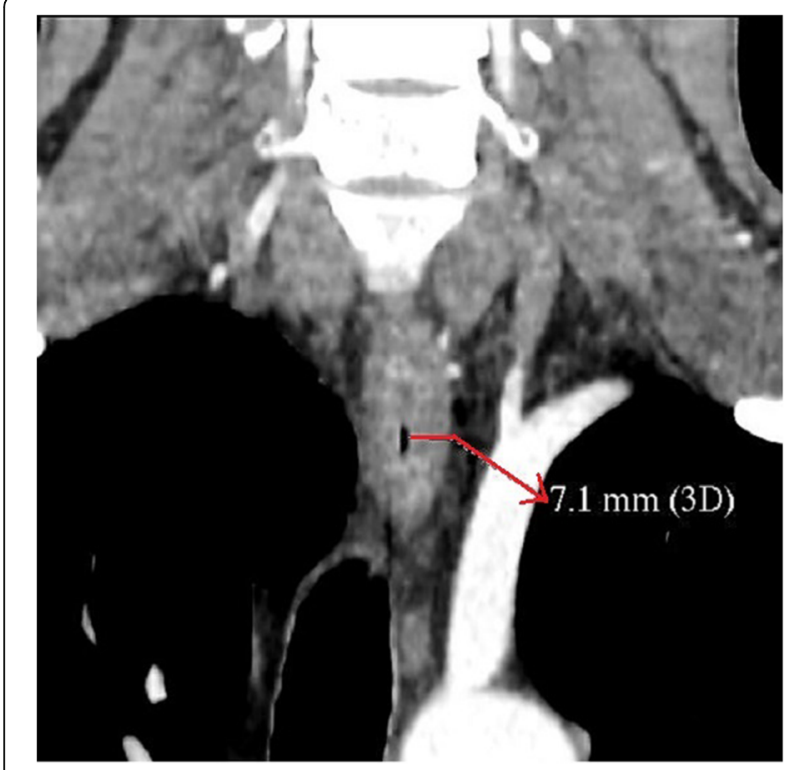

Fig. 3 A thickening of the esophageal wall in a CT scan administered intravenously, which caused an amelioration of esophageal discomfort. He was discharged in a good general condition with a recommendation of a diet based on soft consistency meals, oral PPI and prokinetic drugs administration and the next follow-up in a month.

\section{Discussion and conclusions}

In the 1886 German dermatologist Heinrich Koebner formed an idea of EB, a heterogenous group of genetically transmitted disorders comprising several blistering muco-cutaneous diseases with a monogenic basis and either autosomal dominant or autosomal recessive mode of inheritance. EBS is the most common form in western countries and in general has less severe skin lesions in comparison to JEB or DEB. The herlitz subtype of JEB is less prevalent than the nonherlitz JEB, but both might involve enamel hypoplasia. Skin scarring is a crucial symptom of the herlitz JEB subtype. What is more, mucosal surfaces of the esophagus, upper airway and cornea might also be affected. On the other hand, extracutaneous manifestation is not typical for the nonherlitz JEB. Dominant form of DEB is associated with the formation of skin 




Fig. 4 A narrowing of upper esophageal lumen (red line in picture a) and two esophageal diverticula (red line in picture b) in a barium swallow test

blisters at birth $[3,4]$. Recurrent involvement of the esophagus with subsequent scarring and stenosis can be observed among these patients. Recessive form of DEB is the most severe type of EB and finally leads to disfiguring skin scars, hand and foot deformities, growth retardation and failure to thrive. In addition to skin blistering, photosensitivity and skin pigmentation are characteristic features of KS. EB might involve extra-cutaneous manifestation, leading to severe complications in the eye, nose, oral cavity, ear, larynx and upper respiratory tract. Genitourinary complications (scarring of the glans penis or vaginal vestibule, urethral strictures leading to hydroureter and hydronephrosis) together with musculoskeletal involvement reflected by joints contractures, muscular dystrophy and pseudosyndactyly due to extensive blistering and scarring in DEB are also possible [5-7]. Anemia, usually present in patients with JEB and recessive DEB, heart involvement caused by micronutrient deficiencies and transfusion related iron overload might result in cardiomyopathy. There is also a tendency to develop skin cancers (squamous cell carcinoma, basal cell carcinoma and melanoma) among patients with EB. Gastrointestinal manifestation might occur in several EB subtypes and the esophagus is the most commonly affected due to repeated blistering and scarring, eventually followed by stenosis. Dysphagia, odynophagia and malnutrition belong to the most typical symptoms. They can be even exacerbated by accompanying gastroesophageal reflux disease. Pyloric atresia, painful perianal blistering and anal canal stenosis together with constipation might also occur [8-14]. In presented patient an extra-cutaneous manifestation of EB was reflected by long-lasting esophageal involvement and its stenosis. It is worth emphasizing that this patient is to our knowledge the oldest one in Poland diagnosed with EB. Nowadays an effective therapy for curing EB does not exist. No drugs are known to correct the underlying molecular defects. Even an anti-collagenase strategy, investigated in various surveys, based on phenytoin or tetracyclines, did not improve the blistering or epithelial disadhesion in EB significantly or consistently. Other recent studies focus on the suppression of transforming growth factor beta-1 (TGF$\beta 1)$ and reduction of fibrosis in this mechanism. Losartan, an angiotensin II type 1 receptor antagonist was proved to down regulate TGF- $\beta 1$ activators (e. g. thrombospondin 1) and to improve the course of RDEB. Immunosuppressant drugs like cyclosporine, mycophenolate mofetil and tumor necrosis alpha (TNF- $\alpha$ ) inhibitor etanercept were also trialled, however none of them was indicated in chronic therapy of EB. Numerous potential therapies based on cell therapies (allogeneic fibroblasts, mesenchymal stromal cells, bone marrow transplantation), protein replacement and genes modification have been explored. However, further investigations must still be conducted to clarify this issue [15-18]. A modification of diet texture to soft, puree and liquids is the first step in the management of dysphagia in EB patients. If esophageal dilatation is required, endoscopic procedures are usually performed - with the use of a balloon catheter or a bougie. Nevertheless, in the most severe cases of esophageal stenosis, placement of a gastrostomy tube is recommended. Because of a broad range of complications, the treatment of EB patients must be based on a coordinated multidisciplinary approach and extend from psychological support together with dressings and padding blisters to the management of systemic complications [19-22]. Despite great advances in medicine, a targeted therapy in the course of EB has not been established yet.

\section{Additional file}

Additional file 1: Timeline table (DOCX $15 \mathrm{~kb})$

\section{Abbreviations}

BMI: Body mass index; DEB: Dystrophic epidermolysis bullosa;

EB: Epidermolysis bullosa; EBS: Epidermolysis bullosa simplex; JEB: Junctional epidermolysis bullosa; KS: Kindler syndrome; PPI: Proton pump inhibitor; TGF-

$\beta 1$ : Transforming growth factor beta-1; TNF-a: Tumor necrosis alpha 


\section{Acknowledgements}

Not applicable.

\section{Funding}

No funding was received.

\section{Availability of data and materials}

All data generated or analyzed during this study are available from the corresponding author on reasonable request.

\section{Authors' contributions}

$\mathrm{AM}$ and $\mathrm{BPK}$ analyzed and interpreted the patient data, $\mathrm{LB}$ and $\mathrm{MD}$ performed radiological investigations, AM and $\mathrm{HCL}$ were major contributors in writing the manuscript. All authors read and approved the final manuscript

\section{Ethics approval and consent to participate}

Not applicable.

\section{Consent for publication}

The patient signed an informed consent form and agreed to present his medical history together with photos.

\section{Competing interests}

The authors declare that they have no competing interests.

\section{Publisher's Note}

Springer Nature remains neutral with regard to jurisdictional claims in published maps and institutional affiliations.

\section{Author details}

'Department of Gastroenterology with Endoscopy Unit, Medical University of Lublin, Jaczewski Str, Lublin 820-954, Poland. 'Department of Radiology and Nuclear Medicine, Medical University of Lublin, Jaczewski Str, Lublin 820-954, Poland.

\section{Received: 2 October 2017 Accepted: 20 March 2018}

Published online: 13 April 2018

\section{References}

1. Esposito S, Guez S, Orenti A, Tadini G, Scuvera G, Corti L, et al. Autoimmunity and cytokine imbalance in inherited epidermolysis bullosa. Int J Mol Sci. 2016:17:10

2. El Hachem M, Giancristoforo S, Diociaiuti A. Inherited epidermolysis bullosa. G Ital Dermatol Venereol. 2014;149:651-62.

3. Fine JD, Bruckner-Tuderman L, Eady RA, Bauer EA, Bauer JW, Has C, et al Inherited epidermolysis bullosa: updated recommendations on diagnosis and classification. J Am Acad Dermatol. 2014;70:1103-26.

4. McGrath JA. Recently identified forms of epidermolysis bullosa. Ann Dermatol. 2015:27:658-66.

5. Has C, Nyström A. Epidermal basement membrane in health and disease. Curr Top Membr. 2015:76:117-70.

6. Watkins J. Diagnosis, treatment and management of epidermolysis bullosa Br J Nurs. 2016:25:428-31.

7. Bruckner-Tuderman L, Has C. Disorders of the cutaneous basement membrane zone - the paradigm of epidermolysis bullosa. Matrix Biol. 2014;33:29-34.

8. Soro L, Bartus C, Purcell S. Recessive dystrophic epidermolysis bullosa: a review of disease pathogenesis and update on future therapies. J Clin Aesthet Dermatol. 2015;8:41-6.

9. Zidorio AP, Dutra ES, Leão DO, Costa IM. Nutritional aspects of children and adolescents with epidermolysis bullosa: literature review. An Bras Dermatol. 2015;90:217-23.

10. Shinkuma S. Dystrophic epidermolysis bullosa: a review. Clin Cosmet Investig Dermatol. 2015;8:275-84.

11. Gorell ES, Nguyen N, Siprashvili Z, Marinkovich MP, Lane AT. Characterization of patients with dystrophic epidermolysis bullosa for collagen VII therapy. Br J Dermatol. 2015:173:821-3.

12. Bruckner-Tuderman $L, M c G r a t h ~ J A$, Robinson EC, Uitto J. Progress in epidermolysis bullosa research: summary of DEBRA International research conference 2012. J Invest Dermatol. 2013;133:2121-6.
13. Boeira VL, Souza ES, Rocha Bde O, Oliveira PD, Oliveira Mde F, Rêgo VR, et al. Inherited epidermolysis bullosa: clinical and therapeutic aspects. An Bras Dermatol. 2013;88:185-98

14. Elluru RG, Contreras JM, Albert DM. Management of manifestations of epidermolysis bullosa. Curr Opin Otolaryngol Head Neck Surg. 2013;21:588-93.

15. Rashidghamat E, McGrath JA. Novel and emerging therapies in the treatment of recessive dystrophic epidermolysis bullosa. Intractable Rare Dis Res. 2017;6:6-20.

16. El-Darouti MA, Fawzy MM, Amin IM, Abdel Hay RM, Hegazy RA, Abdel Halim DM. Mycophenolate mofetil: a novel immunosuppressant in the treatment of dystrophic epidermolysis bullosa, a randomized controlled trial. J Dermatolog Treat. 2013:24:422-6.

17. Gubinelli E, Angelo C, Pacifico V. A case of dystrophic epidermolysis bullosa improved with etanercept for concomitant psoriatic arthritis. Am J Clin Dermatol. 2010;11(Suppl 1):53-4.

18. Nyström A, Thriene K, Mittapalli V, Kern JS, Kiritsi D, Dengjel J. Losartan ameliorates dystrophic epidermolysis bullosa and uncovers new disease mechanisms. EMBO Mol Med. 2015;7:1211-28.

19. De Giuseppe R, Venturelli G, Guez S, Salera S, De Vita C, Consonni D, et al. Homocysteine metabolism in children and adolescents with epidermolysis bullosa. BMC Pediatr. 2016:16:173.

20. Webber BR, Tolar J. From marrow to matrix: novel gene and cell therapies for epidermolysis bullosa. Mol Ther. 2015;23:987-92.

21. Wu W, Lu Z, Li F, Wang W, Qian N, Duan J, et al. Efficient in vivo gene editing using ribonucleoproteins in skin stem cells of recessive dystrophic epidermolysis bullosa mouse model. Proc Natl Acad Sci U S A. 2017;114:1660-5.

22. Bremer J, Bornert O, Nyström A, Gostynski A, Jonkman MF, Aartsma-Rus A et al. Antisense oligonucleotide-mediated exon skipping as a systemic therapeutic approach for recessive dystrophic epidermolysis bullosa. Mol Ther Nucleic Acids. 2016:5:10.

\section{Submit your next manuscript to BioMed Central and we will help you at every step:}

- We accept pre-submission inquiries

- Our selector tool helps you to find the most relevant journal

- We provide round the clock customer support

- Convenient online submission

- Thorough peer review

- Inclusion in PubMed and all major indexing services

- Maximum visibility for your research

Submit your manuscript at www.biomedcentral.com/submit 